\title{
One Year Since the First and Only Organ Procurement Case from a Brain- Dead Child Donor Under 6 Years of Age in Japan (Case Report)
}

\section{Yutaka Kato*}

Graduate School of Medicine, Dentistry and Pharmaceutical Sciences, Okayama University, Japan Society for the Promotion of Science, Japan

\begin{abstract}
The enforcement of the revised Act on Organ Transplant of Japan in July 2010 paved the way for organ procurement from a child donor. After the revision, a male child who was admitted to the Toyama University Hospital in June 2012 became the second brain death and organ procurement case in the under-15 age group in Japan, and the first case of a child donor aged less than 6 years. Since then, a year has passed without any new donors. This situation epitomizes the current challenges involved in organ donation from brain-dead donors in Japan. This case report describes the first and only organ procurement case from a brain-dead child donor under 6 years of age in Japan, and highlights the issues of the case, focusing on the problem of provisions for preventing an abused/neglected child patient from becoming an organ donor, which can have implications for the organ procurement practice overseas.
\end{abstract}

\section{Introduction}

With the enforcement of the revised Act on Organ Transplant of Japan in 2010 procurement of organ from child donors became possible [1]. After the revision, a male child aged over 10 years, who died in April 2011, was the first Japanese case declared to be based on neurologic (brain death) criteria and organ procurement from a patient under the age of 15 years [2]. The case described in this report is the second brain death and organ procurement case in the under-15 year's age group in Japan, but the first case of a child donor aged less than 6 years. In the current practice in Japan, the age of 6 is an important demarcation line, as stricter criteria should be met for patients less than 6 years of age. A detailed description of this case is intended to shed some light on the reasons why this case still remains to be the only organ donation case from a child under the age of 6 .

\section{General Background}

Despite brain death, or neurologic death, having been gradually recognized as human death over the past few decades worldwide, in Japan one can still be exempt from death determination based on neurologic criteria even if one enters into a state of brain death [3].

Under the 1997 Act on Organ Transplantation, which was enacted after a heated, prolonged national debate on brain death and organ transplantation and as a result of compromises in the Diet (Japanese Parliament), death determination based on neurologic criteria was applied only to those cases who had consented to donating their organs and whose family did not refuse organ procurement after determination of brain death. This way, the dead donor rule, which refers to an ethical norm whereby vital organs should be procured only from dead patients, is met. Otherwise, death determination was performed on entrenched cardio-pulmonary (triad of death) criteria, which did not determine brain death. Consent by the patient himself/ herself to donate organs in the brain death state was considered indispensable for the implementation of death determination based on neurologic criteria.

The compromises in the Diet resulted in the restrictive provisions of this act. And the problem of the significant shortage of transplantable organs remained unresolved. The first revision was expected within 3 years of the enactment but it was substantially delayed. The Act was revised as late as 2009 and the revision went into effect the following year. Although the double standard scheme within the 1997 act, which allowed one to be exempt from brain death determination even in the case of brain death, was considered as transient, death determination based on brain death criteria remained exclusively limited to organ donors. Cardio-pulmonary criteria continued to be the default definition of death.

Importantly, the revision enabled determination of death based on neurologic criteria and organ procurement from a child patient (a child younger than 12 weeks is still excluded). This was made possible due to the relaxed conditions on consent by the patient. Because the intent and consent by a child under the age of 15 in healthcare is legally invalid in Japan (a person under 15 years old is considered to be ineligible to make a legally valid testament), a child patient under the age of 15 was not considered able to give valid consent for brain death determination and organ donation. In the revised act, organ procurement from patients whose will is unknown or who could not give legally valid consent is endorsed, as long as the family consents. While not only the patients themselves but also their families are entitled to refuse brain death determination, significantly, unless otherwise instructed, the patient is assumed to be willing to donate organs. But such altruistic understanding of a person is, in the current form of the Act, disguised as familial or surrogate decision-making, which appeared more acceptable as well as familiar to the Japanese public.

\section{Case}

An outline of the case reconstructed from publications and media coverage is as follows [4-9].

\section{Consent by the Family to the Determination of Brain Death and Organ Donation}

In June 2012, a male child, who was under 6 years old, was admitted

*Corresponding author: Yutaka Kato, Graduate School of Medicine, Dentistry and Pharmaceutical Sciences, Okayama University, Japan Society for the Promotion of Science, Japan, E-mail: yk.yutaka.kato@gmail.com

Received July 13, 2013; Accepted July 27, 2013; Published August 07, 2013

Citation: Kato Y (2013) One Year Since the First and Only Organ Procurement Case from a Brain-Dead Child Donor Under 6 Years of Age in Japan (Case Report). J Clin Res Bioeth 4: 155. doi:10.4172/2155-9627.1000155

Copyright: (c) 2013 Kato Y. This is an open-access article distributed under the terms of the Creative Commons Attribution License, which permits unrestricted use, distribution, and reproduction in any medium, provided the original author and source are credited. 
to Toyama University Hospital in Toyama Prefecture and diagnosed with hypoxic encephalopathy, i.e. a lack of oxygen to the brain. On the $7^{\text {th }}$ of June, the medical staff at the hospital told the family of the patient that he was suffering from severe cerebral disorder. At that time, the family conveyed their wish to donate organs. On the $9^{\text {th }}$, the family requested further information on organ donation from the brain death state. On their request, coordinator(s) of the prefecture's Japan Organ Transplant Network explained about organ donation to them three times, for 130 minutes in total between the $9^{\text {th }}$ through the $12^{\text {th }}$ of the month. The Japan Organ Transplant Network is the only organization in Japan in charge of organ procurement and allocation. On the $10^{\text {th }}$, the family consented verbally to organ procurement and donation from the patient after the medical staff diagnosed the boy as brain dead (but did not legally determine brain death). On the $12^{\text {th }}$ June, the family was given an explanation by the Japan Organ Transplant Network and consented to the implementation of brain death determination and organ donation at 20:10 of that day. They signed a written consent form. The family consented to procurement and donation of the heart, lungs, liver, spleen, kidneys, small intestine and eyes.

The first death determination process based on neurologic criteria according to the Act on Organ Transplant of Japan started at 9:15 in the morning of the $13^{\text {th }}$ of July. The second brain death determination was completed at $14: 11$ on the following day $\left(14^{\text {th }}\right)$. The interval between the two death determinations have to be more than 24 hours. Thus, the child became the first patient under 6 years old to be declared dead based on neurologic criteria conducted for a patient under 6 years old.

Juntaro Ashikari, the Director of the Medical Department of the Japan Organ Transplant Network, gave the above account at a press conference held at the Ministry of Health, Labour and Welfare (MHLW) in Tokyo on the 14th of June.

At the press conference, journalists asked why the patient had entered into the state of hypoxic encephalopathy. But Ashikari refrained from disclosing the details of the causes of brain death. Instead, he stressed that they had focused on and respected the feelings of the bereaved family. Also, he emphasized that they proceeded cautiously through dispatching experienced coordinators who constantly asked about the wishes and intent of the family to ensure that they had not changed their mind. He did not explain whether the patient himself had wished or refused to donate organs before his death.

During the press conference, Ashikari also read the statement of the parents: "Though our mischievous son often caused us trouble, we spent great times together. His death is sad. But we hope our son will live on as parts within someone else's body and we are proud of our son for accomplishing this (organ donation).

\section{Exclusion of an Abused or Neglected Child}

The supplementary provision of the Act on Organ Transplant added in 2009 prohibits organ procurement from a child patient suspected of being abused or neglected [10,11]. Therefore, in the case of organ procurement from donors who are under 18 years old, it is obligatory to ascertain that the patient had not been abused or neglected. In this case, the Japan Organ Transplant Network confirmed with Toyama University Hospital that there was no evidence of maltreatment of the child patient. Ashikari explained that the panel for the prevention of child abuse and the ethics committee of the hospital denied the possibility of abuse or neglect of the child patient. He also revealed that the Network consulted with the prefectural police and a child consultation office. However, according to the media report delivered on July 20,2012, by Yomiuri Shimbun, a hospital official stated that the child consultation office in charge of the residence of the child patient refused to answer inquiries by the medical staff at Toyama University Hospital because a report of child abuse is considered to be private information [12]. The child consultation office eventually replied to the inquiry, but the hospital official pointed out the possibility that the organ procurement could have failed.

\section{Procurement of Organs from the Child Donor}

The director of the Network also mentioned the first organ procurement procedures from the donor below 6 years old, which was scheduled on the afternoon of the following day $\left(15^{\text {th }}\right)$. The heart was to be transplanted in a female child under 10 years old at Osaka University Hospital. And the liver was to be transplanted in a female child under 10 years old at the National Center for Child Health and Development (Tokyo). Both kidneys were to be transplanted to a female patient in her 60s. There was no potential recipient ready to receive his lungs. The pancreas and spleen were not procured for medical reasons. The eye bank would coordinate a recipient for his eyes.

\section{The Verification Committee}

On the 20th of February 2013, the verification committee of the MHLW concluded that the above-described first brain death determination of a patient under 6 years old was implemented properly and the first organ procurement from the brain-dead child donor was also properly conducted [13]. The verification committee stated that two physician members of the committee had conducted a field investigation including an interview of the doctor in charge at Toyama University Hospital in November 2012.

\section{Situation after the First Case}

One year has passed without any other child donors since the first and only organ procurement case from a brain-dead child donor under 6 years old in Japan. It would be better if this were because there had been no occurrence of brain death in child patients, but unfortunately this is not the case.

Due to the lack of transplantable organs from domestic child donors, families of small children suffering from serious organ malfunction, especially heart disease, find it extremely difficult to obtain a donor. Consequently, despite the Declaration of Istanbul, which criticized organ trafficking, transplant tourism and commercialism, [14] and the high cost of undergoing organ transplant overseas, which often exceeds 1 million US dollars, such families are still forced to go abroad for transplants, as happened before the legalization of brain death determination of children under age 15. Media reports of Japanese children receiving hearts overseas in the last year include Ayuto Shimazu (1 year old), who received a heart at Loma Linda University Hospital in December 2012, Aoi Yoshida (2 years old) at Columbia University in May 2013, and Nagi Jimbo (1 year old) at Columbia University in June 2013.

\section{Discussion}

\section{Reasons for exceptional success}

More than a dozen patients aged less than 15 years are registered in the waiting list for heart donation. As mentioned above, however, there have been only two cases of organ donation from donors under the age of 15 years. The Toyama University Hospital case remains an exceptionally successful one. With regard to the decisions made by the 
family of the child patient, Ashikari, stated that the family themselves wished to donate organs [15]. In a symposium at the $116^{\text {th }}$ Annual Meeting of the Japan Pediatric Society, held in Hiroshima in April 2012, a medical doctor who was involved in the Toyama University Hospital case pointed out that it was possible because the family had discussed organ donation in advance. In this case, the family achieved consensus among family members on brain death determination and organ donation without delay. Also, they indicated their wish to donate organs from their son on the day following the hospitalization. However, today, the Japanese public lacks interest in brain death or organ donation, which can make a consensus necessary for organ donation difficult.

\section{Uniqueness of a child case}

In Japan, determination of brain death and organ procurement from a child under the age of 6 is considered to entail difficulties, such as size matching, prolonged brain death duration, measurement and determination, the feelings of the bereaved, and the possibility of child abuse and neglect.

\section{Size matching}

Organs procured from an adult donor are sometimes too large for a child recipient. For example, the adult heart does not function properly in the body of a child as it gets compressed within a small space. Regarding lungs, Japan's MHLW is currently considering the possibility of transplantation of divided lungs procured from a braindead donor in order to ease the condition of the difference in body height between a donor and a recipient [16].

\section{Prolonged brain death duration - chronic brain death}

"Imminence of asystole" observed in brain dead patients has been a foundation for the understanding of brain death as human death. But there have been reported cases of chronic brain death [17]. Prolonged brain death duration, which is encountered relatively more frequently in the case of a child patient presumably due to greater resilience and plasticity of the brain, has been a major focus of the controversy. Reports on chronic brain death have led some scholars, including Yoshihiko Komatsu (bioethicist) and Tomoko Abe (physician and member of the House of Councilors), to doubt the adequacy of brain death. "The survey study on brain death and organ donation of child patients" refers to cases in which the duration between diagnosis of brain death and cardiac asystole is long (more than a month). This study did not think that these known cases of prolonged brain death duration could affect the validity of death declaration based on neurologic criteria as there had been no case of recovery. However, the study simultaneously highlighted the greater necessity of explanation of the state by medical staff to the family.

\section{Difficulties involved in measurement and determination}

The criteria for legally determining brain death currently used in Japan include deep coma, dilated pupils, loss of brain stem reflexes, flat electroencephalogram, cessation of spontaneous respiration (including apnea test) and the above standards should be met twice over an interval longer than 6 hours in patients 6 years or older. In several cases, brain death determination is not implemented: hypothermia, or low body temperature, (rectal temperature below 32 degrees in the case of patients of 6 years or older and 35 degrees in the case of patients under the age of 6), patients younger than 12 weeks old, etc.

A brain in early childhood is immature in terms of morphology and function. Accordingly, normal findings of electroencephalogram, or brain wave, are different from adults or older children. Also, because of smaller earlobes and crania, fewer electrodes can be used. Moreover, they can be easily affected by cardiac electrogram and respiratory movements because of smaller size of the body. These factors make confirmation of flat electroencephalogram more difficult.

In the Takeuchi Criteria (1985), which became the foundation for the criteria currently used in Japan, a patient under the age of 6 was excluded, due to the lack of evidence and detailed understanding of age-specific neurological activities (ibid.). Basically, the Takeuchi Criteria were considered to be applicable for a child who is between 6 and 15 years old. Japan's Ministry of Health and Welfare, the precursor of the MHLW, founded the task force for brain death criteria for child patients, and the task force published the criteria in 2000. The brain of a child is considered to demonstrate greater resilience and plasticity. In Japan, brain death determination has to be conducted twice in order to completely eliminate error and confirm irreversibility of brain death. The interval between the two determinations should be more than 6 hours in case the patient is aged 6 years or more, and more than 24 hours if the patient is under the age of 6 years because the brain of a child is considered to demonstrate greater resilience and plasticity.

\section{The feelings of the bereaved}

It is often argued in Japan that, in addition to the physiology of the brain of a child, psychological trauma from losing a child at a young age and the lingering regret of not saving a life make organ procurement from a child donor unique.

While a section of the media reported this case favorably using the phrases "a relay of life, [9]" "one way of death watch, [5]" and "a bright ray of hope, [8]" few others have expressed concerns about the feelings of the bereaved family. A media report cited Hiroyuki Yokota, a professor at Nippon Medical School, who commented that: "One big problem in finding organs from small, brain-dead children relates to the feelings of family" and "The highest hurdle is that families have difficulties convincing themselves that their children are brain dead [15]". Death of their child is usually unexpected for the family. Hospital staffs need to explain the family that there is no possibility of miraculous recovery. Moreover, some people question the validity of consent given by the bereaved that must be in psychological trauma after the death of their child. As for lingering regret of not saving a life, some have expressed concern whether utmost treatment was provided to save the child's life before being declared brain-dead, as in the case of Takahito Togawa, the representative of a group of people who lost their family members in traffic accidents (In Japan, due to fewer cases of firearms and illicit drugs, traffic accident casualties have been a significant source of transplantable organs), who was cited in the same media report. In relation to this, historically, the effort of improving pediatric emergency care of the medical society coincided with the preparation for the revision of the Act.

\section{The possibility of child abuse and neglect}

Ii is not uncommon that child abuse causes injury to the head that leads to brain death. The passion to avoid organ procurement from an abused or neglected child patient is apparently characteristic of the practice of Japan. Exclusion of an abused or neglected child as an organ donor was not mentioned in "the criteria for determining brain death of a child (2000)." The Japan Pediatric Society recommended the exclusion in 2005 in preparation for brain death determination and organ donation of a child patient. The supplementary provision of the revised Act on Organ Transplantation of Japan excludes "a case in which abused or neglected child is dead" from death determination 
based on neurologic criteria. Importantly, what is excluded in the Act is not a case in which a child is dead due to abuse or neglect. Thus, even if the cause of death has nothing to do with abuse or neglect, the child cannot be an organ donor from brain-dead state. Moreover, the Manual aims at excluding as many as possible cases suspected of being of abused or neglected children. Thus, excluded cases are also expected to include cases of children neither abused nor neglected.

\section{Reasons for excluding an abused or neglected child}

The primary reason for excluding an abused or neglected child is the preservation of evidence (i. e. a body of the abused or neglected child) for judicial process [18]. The second reason is the qualification of parents for parental rights. Ikuya Ueta, the Director of pediatric intensive care unit at Shizuoka Children's Hospital, who cooperated in the research funded by the MHLW, notes that parents who abused or neglected their child are no longer considered eligible for deciding the best interest of the child and that, consequently, they cannot consent to organ procurement and donation in the brain death state of their child [19]. One reason behind this is that the Japanese courts, compared to the courts in United States, are reluctant to intervene and terminate parental rights. The third reason is the concern about the possibility that a parent physically abuses their child to save someone else, for example, another child of their own. In a situation like this, some parents may not hesitate to be convicted. In Japan, where the revised Act on Organ Transplant allows the family of the donor to donate the organ to their kin on a priority basis, this possibility is not totally unlikely. Fourth, some have mentioned the need to prevent the bereaved from deciding to donate organs from their child for their own particular ambition or eagerness for fame (ibid.). The fifth reason is the underlying premise of organ donation from the brain death state that it should be based on beneficence and altruism, which leads some to sense the need to carefully prevent the practice from being contaminated by injustice and malfeasance, that is, abuse or neglect in this case.

Nevertheless, some of the above reasons do not appear to be strong enough to overturn the offer of the bereaved to donate organs of their brain dead child. The third problem can and should be dealt with individually. Different types of abuse and neglect (psychological, physical or neglect) can be treated differently. Also, it seems questionable to me that the demand for securing possible suspects prevails over the demand for saving lives.

\section{Cooperation between medical institutions and child consultation offices}

In this case, the child consultation office in charge at first refused to answer inquiry by the hospital (as mentioned above, the office replied to the inquiry later). The above broad exclusion is explained as the logical result of the currently insufficient cooperation between health institutions and police/child consultation offices [21]. According to a survey conducted by the MHLW in December, 2012, only 34 out of 69 municipalities replied that a child consultation office could respond to inquiries on possible child abuse and neglect by medical institutions. It is apparent that the relation between child consultation offices and medical institutions should be reconsidered. Japan does not have detailed database on maltreatment of children comparable to the National Child Abuse and Neglect Data System (NCANDS) of the United States. Many have pointed out the necessity to improve collaboration between medical institutions and child consultation offices [16]. However, considering that medical institutions financially benefit from conducting organ donation, independence of child consultation offices should be maintained to avoid the improperly close relation between institutions sometimes observed in the country.

\section{Conclusion}

This report described a case of death determination based on neurologic criteria and organ donation of a male child who was admitted to the Toyama University Hospital in the mainland of Japan in June, 2012. The child patient was the second brain death determination and organ procurement case under 15 years old in Japan and the first case of a child under 6 years of age after the revision of the Act on Organ Transplant of Japan (1997) in July, 2009. The original Act on Organ Transplant (1997) did not allow brain death determination of a patient under 15 years of age. The enforcement of the revised Act in 2010 enabled death determination based on neurologic criteria of and organ procurement from a child donor. However, even three years after the enforcement of the revised Act, this case remains the only organ procurement case from a brain-dead child donor under 6 years old in Japan. Apparently, the backgrounds specific to Japan - including the accumulated discourses on brain death and organ determination in the past national debate, the emphasis on the family (rather than individuals), the critical role of subjectivity (intent of a patient) in brain death determination and organ donation - cast a shadow over the current transplantation practice of the country. Among the most conspicuous is the passion of the country to avoid organ procurement from an abused or neglected child patient. Through describing the case, issues and challenges involved in the medical practice are also presented, together with skepticism toward some of the rationales behind the exclusion of an abused or neglected child as an organ donor. Nevertheless, Japan's precaution can be a canary in a coal mine for the transplantation practice of other countries with little attention to potential problems involved.

\section{References}

1. Law on Organ Transplantation (1997) 16th law.

2. Matibag GC (2013) Japan's first child organ transplant donor.

3. Ministry of Health, Labour and Welfare website on the revision of the Act on Organ Transplantation.

4. Kyodo News (2012) Organs of brain-dead boy are harvested, Japan.

5. Kyodo News (2012) The first brain death determination of a patient under 6 years old, Japan.

6. Japan Today (2012) Doctors remove organs of brain-dead boy, Japan.

7. Jiji Press (2012) The first organ donation case from a patient under 6 years old.

8. The Asahi Shimbun (2012) Organ transplant from child 'a bright ray of hope.

9. The Sankei Shimbun (2012) The brain death determination of a patient under 6 years old, Japan

10. Guidelines for implementing the Act on Organ Transplant.

11. The Yomiuri Shimbun (2012) The child consultation office refused the inquiry on abuse and neglect for organ transplant since it is private information.

12. The Sankei Shimbun (2013) The verification committee concludes that the first organ procurement from a patient aged under 6 was properly conducted.

13. The Declaration of Istanbul on Organ Trafficking and Transplant Tourism.

14. The Sankei Shimbun (2013) One year since the organ donation from a patient under the age of 6

15. The Asahi Shimbun Digital (2013) The MHLW is reconsidering easing the condition of the difference in body height between a donor and a recipient in lung transplantation.

16. Shewmon DA (1995) Chronic "brain death": meta-analysis and conceptual consequences. Neurology 51:1538-1545.

17. Nukui $H$. Manual for excluding possibly abused or neglected children from potential organ donors under the state of brain death 
Citation: Kato Y (2013) One Year Since the First and Only Organ Procurement Case from a Brain-Dead Child Donor Under 6 Years of Age in Japan (Case Report). J Clin Res Bioeth 4: 155. doi:10.4172/2155-9627.1000155

Page 5 of 4

18. The manual for legal determination of brain death.

19. The minutes of the 8 th meeting (2010) of the task force for indication of intention regarding organ donation and organ donation from a child, Japan.
20. http://book.geocities.jp/shizu_pediatrics46/question.html

21. Yamada F. Examination of "Manual for excluding possibly abused or neglected children from potential organ donors under the state of brain death.

This article was originally published in a special issue, Case Reports in Bioethics handled by Editor. Azetsop J, Department of Medical Ethics, South

Africa 